\title{
MICRO-RAMAN SPECTROSCOPY OF DECORATED POTTERY OF THE DIAGUITA CULTURE FROM IV REGION, CHILE $\left(9^{\mathrm{TH}}-15^{\mathrm{TH}}\right.$ CENTURY AD)
}

\author{
F. OSORIO', G. DÍAZ FLEMING ${ }^{*}$, U. MARTÍNEZI, M.M. CAMPOS-VALLETTE ${ }^{2}$, E. CLAVIJO2, \\ A.E. ALIAGA', M. FERNANDA ESPINOSA ${ }^{3}$ AND D. BRACCHITTA ${ }^{3}$
}

\author{
${ }^{1}$ Universidad de Playa Ancha, Fac. Ciencias Naturales y Exactas, POBox 34-V, Valparaíso, Chile. \\ ${ }^{2}$ Universidad de Chile, Facultad de Ciencias, POBox 653 Santiago, Chile. \\ ${ }^{3}$ Centro Nacional de Conservación y Restauración (CNCR), DIBAM, Recoleta 683, Santiago, Chile
}

\begin{abstract}
Raman spectroscopy pigments on decorated antique Chilean pottery belonging to the Diaguita`s culture deposited in Museum of Limarí, have been studied by using Raman spectroscopy. Four ceramic fragments from the unknown contexts were examined. Four colors were found with certainty: red, black, brown and white. Quartz and manganese (kempite) salts, as well as different types of oxide pigments: hematite, tenorite and possibly goethite, were identified.
\end{abstract}

Keywords: Raman spectroscopy; pigment analysis; archaeometry; Diaguita ceramics

\section{INTRODUCTION}

The knowledge of the materials involved in artistic and cultural heritage, allows a better understanding of our civilization, and an improvement of the restoration and conservation methods. But, until recently, the study of works of art remained mainly the concern of research by art historians because the scientific techniques required a quantity of materials unacceptable for the integrity of the works. In fact, spectroscopic analyses are the most frequently used methods in the field of cultural heritage ${ }^{1,2}$. Among them, Raman spectrometry is one of the most powerful due to its characteristics. The unique properties of this technique involve non-destructive nature, no sample preparation, reliability, specificity and sensitivity ${ }^{3-5}$. Thus, Raman spectrometers have become the instrument of choice when analyzing archaeological artifacts and pigments on art works ${ }^{6}$.

It is also amenable to in situ analysis, based in the development of fiber optics technology ${ }^{7-9}$. During the 1990s, the development of CCD as spectroscopy detectors and lasers led to cheaper and easy-to-use Raman spectrometers. Due to these special features, the literature shows that Raman spectroscopy has been studied extensively and applied widely.

The main applications in heritage studies concern the identification of pigments on various kinds of support materialities. Pigments, together with binders and fillers, give important information about artists, artistic schools or technological evolution; mainly inorganic compounds, pigments are good candidates for Raman identification. In order to enhance its efficiency, Raman spectrometers are typically coupled with a microscope in order to observe the sample and can take a Raman spectrum from a small area down to one micrometer 10,11 . The use of Raman microscopy gives information on the microstructure of analyzed samples and also improves the spatial resolution. Nevertheless, its meaningful disadvantage still lies in the formation of undesirable fluorescence, which is an accompanying phenomenon of measurements of diverse materials and which is very difficult to forecast.

This paper reports on the micro-Raman spectroscopic investigation of pigments in decorated pottery from the Museum of Limarí, in Chile. These objects are belonging of the Diaguita culture, one of the distinct original people mainly settled during the pre-Columbian period in the III and IV region of the actual Chilean territory. Far as we know, this is the first time that this noteworthy kind of ceramics from the Valle del Elqui has been investigated by means of micro-Raman spectroscopy.

\section{The Diaguita's people}

The Diaguita's culture was mainly developed in different stages between the $9^{\text {th }}$ and $15^{\text {th }}$ century $\mathrm{AD}$; this culture is recognized in the preColumbian American territory because of the plastic richness of its pottery 12. Geographically, the Diaguita culture spreads in the north of Chile over the transversal valleys of the Copiapó, Huasco, Elqui, Limarí and Choapa rivers, $18^{\circ}$ to $31^{\circ}$ south latitude. Three development phases in the Diaguita's culture have been recognized on the basis of the complexity in the manufacturing of pottery's artifacts. The last phase corresponding to Inca rule period ${ }^{13}$.

\section{EXPERIMENTAL}

Objects and sampling

It has been worked on 4 samples of ceramics fragments belonging to the Museum of Limarí; samples are arbitrarily classified as L01, L02, Q01 and R01. See Fig. 1. The analysis of these samples was focused on presenting the colors, the main ones being black (bl), white (wh), red (re) and brown (br). The tonality of these colors is visually classified as intense (int) or tenuous (ten). The rating given to identify the area of the samples analyzed is: L01wh.int, L01wh.ten, L02bl.int, L02bl.ten, Q01bl.ten, Q01br.ten, Q01wh.int, R01br.int, R01br.int and R01wh.int.

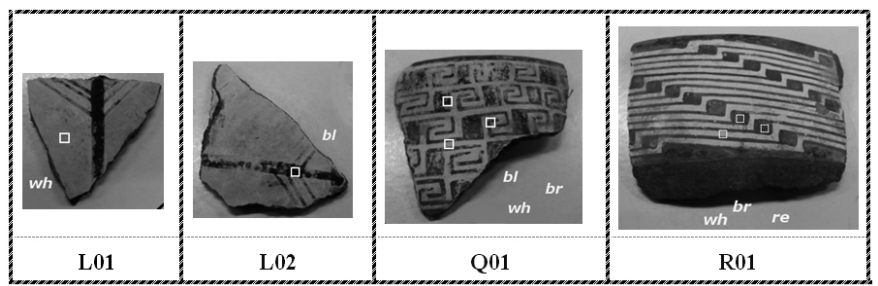

Figure 1. Diaguita decorated potteries from the archaeological site of Valle del Elqui, Las Animas. The samples are arbitrarily classified as L01, L02, $\mathrm{Q} 01$ and R01. The colored areas are displayed by squares and correspond to black (bl), white (wh), red (re) and brown (br) colors.

Pieces labeled L01 and L02 are fragments of triangular shaped ceramic having two main shades of color, black and white, see Fig. 1. In both pieces is found very deep black lines, almost entirely in perfect maintenance. Regarding, to the white color two cases are presented, very intense white light in some areas and a rather faint tonality in other zones. The Q01 pottery fragment, displays 3 colors, white, black and red-brown, see Fig.1, this fragment have three sectors appear: intense white, deep black and a faint brown. The R01 pottery fragment is the best preserved in terms of visual coloring, see Fig. 1. This part shows three quite deep hues. Micro-Raman spectra of all sectors, the bright white, deep red and brown were scanned.

\section{Raman spectroscopy}

The Raman measurements were performed using a Renishaw microRaman RM 1000 spectrometer, equipped with laser lines 514, 633 and 785 $\mathrm{nm}$. The apparatus is coupled to a Leica microscope and a CCD camera cooled electrically. The Raman signal was calibrated to the $520 \mathrm{~cm}^{-1}$ line of silicon and lens of 50x objective. The laser power on the sample is about $2 \mathrm{~mW}$. Acquisition time was set between 10 and $20 \mathrm{~s}$ per accumulation; the average of accumulations was 10 with spectral resolution of $4 \mathrm{~cm}^{-1}$. The spectra were recorded between 100 and $1800 \mathrm{~cm}^{-1}$. Spectral recording conditions and the 
choice of the laser line to be used is selected in order not to cause degradation of the sample; in this sense, the 633 and $785 \mathrm{~nm}$ lines were used.

Raman spectra of samples which were impossible to be accommodated in the area of logging instrumentation, were obtained by using a spectrophotometer Raman portable model MiniRamanTM series III Thumbnail TE, equipped with a laser line of $785 \mathrm{~nm}$ and one meter of optical fiber.

\section{RESULTS AND DISCUSSION}

White zones. In the L01wh.int, L01wh.ten, Q01wh.int and R01wh.int zones, the micro-Raman spectrum presents intense fluorescence, see Fig. 2A. However, it was possible to identify the characteristic sharp band of quartz at $464 \mathrm{~cm}^{-1}$. This normal mode attributed to the Si-O stretching vibration, showing some degree of shifting wavenumbers due to variations in the crystallinity of the sample, has been reported by several authors ${ }^{14-17}$.

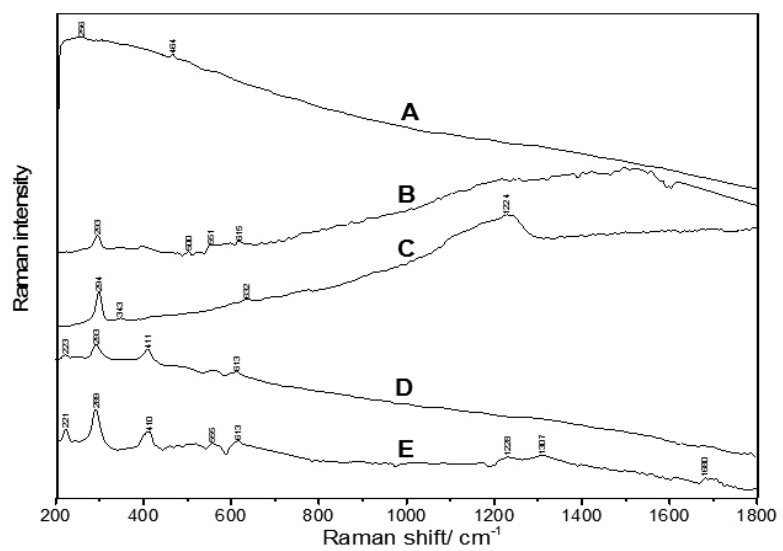

Figure 2. Raman spectra collected from the Diaguita decorate potteries. A) White color was attributed to quartz. B) Black color presenting characteristics bands of kempite. C) Intense black color presenting characteristics bands of tenorite. D) Red color was assigned to hematite. E) Brown color was attributed to hematite and tenorite or goethite mineral.

Black zones. Fig. 2B and 2C illustrates micro-Raman spectra of the black coloration part of the L02.bl.int, L02.bl.ten y Q01.bl.ten zones, as representative spectra of the investigated samples. The micro-Raman spectra of these samples indicated that the regions with similar colors were not homogeneous and did not necessarily give similar spectrum, pointing out different composition. It was initially believed that the black pigment used to paint these ceramics was only a manganese salt $\left(\mathrm{Mn}_{2} \mathrm{Cl}(\mathrm{OH})_{3}\right)$ or kempite ${ }^{14}$, which was found in $\mathrm{L} 02 \mathrm{bl}$. ten and Q01bl.ten, because of the band detected at $293 \mathrm{~cm}^{-1}{ }^{14}$. In samples where deep black dashes were observed (L02bl.ten), the Raman spectrum also present bands at 343, 632 and $1224 \mathrm{~cm}^{-1}$ belonging to copper oxide (II) or tenorite ${ }^{14}$, as is observed in Fig. 2C. Further, less fluorescence is presented in L02bl.int. The copper presence it has been reported in the black pigments of Pre-Columbian Chilean potteries ${ }^{18}$.

Red zone. Concerning the red color, Raman spectroscopic studies of the composition of archaeological objects (ceramics and other clay pottery) revealed that hematite, $\alpha \mathrm{Fe}_{2} \mathrm{O}_{3}$, or derivatives such as $\mathrm{Fe}_{3} \mathrm{O}_{4}, \mathrm{FeO}$ and $\mathrm{FeO}(\mathrm{OH})$, were commonly used as pigments ${ }^{15-20}$. 19-24 In accordance to this fact, the micro-Raman spectrum of sectors that present red coloration, Fig. 3D, in R01re.int, shows characteristics bands of hematite at 223, 289, 411 and $613 \mathrm{~cm}^{-1}$, therefore suggesting this compound as the red pigment present in the ceramic sample. Hematite has also been found in different red tonalities from orange to brown in the decoration of Viluco and Chilean Diaguita type ceramics ${ }^{21}$. Additional bands reported in the literature for this compound ${ }^{22,26,27}$ at 247 and $498 \mathrm{~cm}^{-1}$, were not observed in the present work.

Brown zones. The micro-Raman spectrum (Fig. 2E) of the Q01br.ten and R01br.int zones presents several bands which are in the same or very close to those wavenumbers registered for hematite $\left(221,289,410,613 \mathrm{~cm}^{-1}\right)$ as well as bands at 1228 and $1307 \mathrm{~cm}^{-1}$, which can proceed from tenorite. Also it is possible to consider this spectrum as coming from a variety of hematite like $\mathrm{FeO}(\mathrm{OH})$ (goethite) ${ }^{14}$, which color is described, among others, as a redbrownish or ochre ${ }^{28,29}$.

\section{CONCLUSIONS}

The determination of chemical components in pottery archaeological objects of Diaguita origin confirmed the effectiveness of micro-Raman spectroscopy in the analysis of these objects. Some chemical components identified were crystalline silicates, namely, quartz, and pigments such as kempite, tenorite, hematite and potentially goethite. Additionally, in the case of the brown color is possible to interpret this tint either as a mix of different pigments or due to only one genuine pigment (goethite). Hematites recognized in the present work, are also detected in the red type color of the Diaguita and Viluco culture and in Norwest Argentinian ceramics Aguada de Portezuelo ${ }^{30}$. The copper content of the black colour appears to be a particularity of Diaguitas, because in other cultures of South America the black pigment content iron, manganese and carbon ${ }^{30-33}$ in their composition. Finally, it is intended that these results will help in revealing the potential of Raman spectroscopy as a tool in analyzing pottery shards and their methods of production in other ancestral cultural groups in Chile.

\section{ACKNOWLEDGEMENTS}

Authors acknowledge projects 1110106 from Fondecyt and FAIP-N-57Arqueol. Chile (2012) for financial support.

\section{REFERENCES}

1. P. Baraldi and A. Tinti, J. Raman Spectrosc., 39, 963 (2008).

2. P. Vandenabeele, H.G.M. Edwards and L. Moens, Chem. Rev., 107, 675 (2007).

3. N.Q. Liem, G. Sagon, V.X. Quang, H. van Tan and P. Colomban, J. Raman Spectrosc., 31, 933 (2000).

4. P. Colomban and F. Treppoz, J. Raman Spectrosc., 32, 93 (2001).

5. L. Burgio, R. J. H. Clark, T. Stratoudaki, M. Doulgeldis and D. Anglos, Appl. Spectrosc., 54, 463 (2000).

6. D. Aglos, S. Curtis and C. Fotakis, Appl. Spectrosc., 51, 1025 (1997).

7. N. Boucherit, A. Hugot-Le Goff and S. Joiret, Corros. Sci., 32, 497 (1991).

8. R.J. Thibeau, C.W. Brown and R.H. Heidersbach, Appl. Spectrosc., 32, 523 (1978).

9. D.L.A. de Faria, S.V. Silva and M.T. de Oliviera, J. Raman Spectrosc., 28, 873 (1997).

10. F. Adar, C. Naudin, A. Whitley, Raman Technology For Today's Spectroscopists, 2004, 22-29

11. G.D. Smith, Robin J.H. Clark, J. Arch. Sci., 3, 1137 (2004)

12. G. Ampuero Brito, Departamento de Extensión Cultural del Ministerio de Educación, 1978.

13. G. Ampuero. Diaguitas. Pueblos del Norte Verde. Museo de Arte Precolombino. 96 pp. 1986.

14. RRUFF Project website, an integrated database of Raman spectra, X-ray diffraction and chemistry data for minerals, http://rruff.info/.

15. P. Gillet, A. Le Cleach, and M. Madon, J. Geophys. Res., 95, 21635 (1990).

16. R.J. Hemley, in "High-pressure research in mineral physics", M.H. Manghnani and Y. Syono (Eds), Terra Scientific Publishing Company and AGU, Tokyo/Washington D.C., pp. 347-360 (1987).

17. K.J. Kingma and R.J. Hemley, Am. Mineral, 79, 269 (1994).

18. M.I. Dinator and J.R. Morales. J. Radioanal. Nucl. Ch., 140, 133 (1990).

19. D. Bikiaris, S. Daniila, S.S. Sotiropoulou, O. Katsimbiri, E. Pavlidou, A.P. Moutsatsou and Y. Chryssoulakis, Spectrochim. Acta Part A, 56, 3 (1999).

20. L. Burgio, R.J.H. Clark and K. Theodoraki, Spectrochim. Acta Part A, 59, $2371(2003)$

21. K. Witke, J. Gotze, R. Röbler, D. Dietrich and G. Marx, Spectrochim. Acta Part A, 60, 2903 (2004)

22. P.S. Porto and R.S. Krishnan, J. Chem. Phys., 47, 1009 (1967).

23. H.G.M. Edwards, S.E.J. Villar, A.R. David and D.L.A. Faria, Analytica Chimica Acta, 503, 223 (2004).

24. R.A. Goodall, J. Hall, R. Viel, P.M. Fredericks, Archaeometry, 51, 95 (2009).

25. J.A. Tuñón López, A. Sánchez Vizcaíno, H. Chiavazza, M. Montejo Gámez, Estudos Arqueológicos de Oeiras,19, Oeiras, Câmara Municipal, 2012, p. 193-202

26. D.L.A. de Faria, S.V. Silva and M.T. de Oliviera, J. Raman Spectrosc., 28, 873 (1997).

27. A.P. Kozlova, S. Sugiyama, A.I. Kozlov, K. Asakura and Y. Iwasawa, Catalysis, 176, 426 (1998).

28. M. Hanesch, Geophys. J. Int., 177, 941 (2009). 
29. http://webmineral.com/data/Goethite.shtml

30. G.A. de la Fuente and J.M. Pérez Martínez. Intersecciones antropol., 2008, n.9, pp. 173-186.

31. M.B. Cremonte, M. Baldini and I.L. Botto. Intersecciones antropol., 2003, n. 4, pp. 3-17.
32. J. Van der Weer, G.D. Smith, S. Firth and R. Clark. J. Arch. Sci., 31, 1429 (2004).

33. G.A. de la Fuente, N. Kristcautzky, G. Toselli and A. Riveros. Estud. atacam. 2005, n.30, pp. 61-78. 